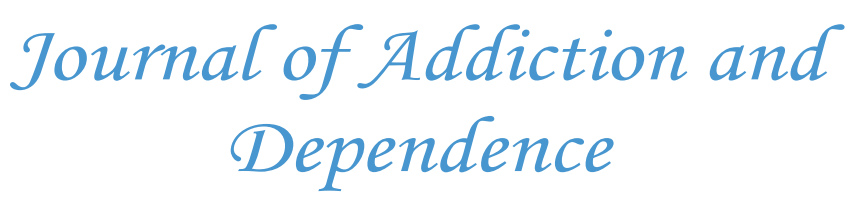

\title{
Role of School Counselor in Mitigating Heroin Usage amongst Adolescents: Implications for the School Counselor Profession
}

\author{
Allison C. Paolini* \\ Assistant Professor of Counselor Education, Kean University, Nathan Weiss Graduate College, NJ, USA
}

*Corresponding author: Allison C. Paolini, Assistant Professor of Counselor Education, Kean University, Nathan Weiss Graduate College, NJ, USA, E-mail: acpaolini@gmail.com

\begin{abstract}
This manuscript will describe the deleterious effects that Heroin usage has on student's academic performance and overall wellbeing. The manuscript will also discuss the instrumental role that school counselors play in mitigating Heroin usage amongst adolescent students. Best practices that school counselors can utilize in regards to reducing Heroin usage amongst adolescents, as well as implications for the school counseling profession will also be addressed.
\end{abstract}

Keywords: Heroin; Academic performance; School counselor; Best practices; Implications

\section{Received Date: June 17, 2016 \\ Accepted Date: September 30, 2016 \\ Published Date: October 06, 2016}

Citation: Paolini, A.C. Role of School Counselor in Mitigating Heroin Usage Amongst Adolescents: Implications for the School Counselor Profession. (2016) J Addict Depend 2(2): 110- 115.

DOI: $10.15436 / 2471-061 X-16-026$

\section{Introduction}

According to the National Institute on Drug Abuse ${ }^{[1]}$, Heroin is an opioid drug that is made from a morphine derivative. It typically appears in a powdery substance and can be smoked, snorted, or injected intravenously. In 2011, 4.2 million Americans ages 12 or older (1.6\%) reported using Heroin at least once in their lives. Approximately, 23\% of individuals who use Heroin become dependent on the drug. Additionally, research has shown that other opioid drugs such as Oxycontin and Vicodin have similar effects on the body to Heroin and have been labeled as gateway drugs to Heroin usage ${ }^{[1]}$. Almost half of young people who inject Heroin indicated abuse of opioids prior to using Heroin. Once Heroin enters the brain it is converted back into morphine, which binds to opioid receptors that control respiration and blood pressure. Heroin abuse is associated with other serious health effects including collapsed veins, pulmonary complications, gastrointestinal issues, and overdoses.

In addition to the harmful Heroin usage has on one's overall health, Heroin usage also has dire consequences on one's academic performance including engaging in risky behaviors, earning lower grades, failing out of school, truancy, and dropping out ${ }^{[2]}$. In a study conducted by Palamar, Shearston,
Dawson, Mateau-Gelabert, and Ompad ${ }^{[3]}$, the researchers conducted a national study composed of high school seniors who engage in non-medical opioid and Heroin usage. The researchers found that $12.4 \%$ of high school seniors reported a lifetime of non-medical opioid usage and as opioid usage increased, so did the likelihood for reporting Heroin usage. Additionally, over three quarters $(77.3 \%)$ of Heroin users reported a lifetime of nonmedical opioid usage. The researchers indicated that females and minority students were less likely to report opioid of Heroin usage in comparison to their male Caucasian counterparts ${ }^{[3]}$. Therefore, those students using nonmedical opioids were more likely to engage in Heroin and other illicit drug usage than those who did not take nonmedical opioids. The researchers also found that students residing in large metropolitan areas were less likely to engage in frequent opiate usage, we well as those students who were religious and or resided with both parents ${ }^{[3]}$.

Cerda, Santaella, Marshall, Kim, and Martins ${ }^{[4]}$, also conducted a study assessing for nonmedical prescription opioid use in childhood and early adolescence and how that can predict transitions to Heroin usage in adults. The researchers found that prior use of nonmedical prescription opioids is a strong predictor 
of heroin use onset in adolescence and young adulthood irrespective of the user's race, ethnicity, or socioeconomic status. Additionally, having early intervention and prevention of nonmedical use of prescription opioids in childhood may mitigate the onset of more severe types of drug use such as heroin at later ages. Thus, being proactive rather than reactive and helping students struggling with opioid usage early on has positive impacts on reducing the likelihood of drug usage later on in life ${ }^{[4]}$.

In accordance with King et al., the researchers evaluated literature on studies conducted regarding the impact of substance abuse on student academic performance. The researchers stipulated that drug usage has a strong relationship with chronic absenteeism in that students who are utilizing drugs are more likely to struggle with truancy, drop out of school, experience a disconnection, have poor self-control, lack of motivation, and are not able to make constructive decisions. Additionally, the researchers indicated that adolescent drug use leads to decreased engagement within school. Substance abuse negatively impacts students' cognitive development, which directly has a dire impact on their academic performance.

\section{Role of School Counselor in Helping Students to Reduce Heroin Usage}

Drug usage is a pervasive epidemic that negatively impacts students of all ethnicities, backgrounds, and socioeconomic statuses. There has been an ongoing Heroin crisis in this country and school counselors play a critical role in identifying and helping students to mitigate substance usage. School counselors are change agents, leaders, advocates, and are responsible for ensuring the academic, personal, social, and vocational success of all students. Teen well-being is an important component in order to decrease substance misuse. In order to mitigate substance misuse school counselors can work with administrators on supporting student academic achievement and promote the importance of an $80 \%$ graduation rate, prevent bullying, prevent, smoking and alcohol usage on school campuses, screen and refer students who are engaging in high risk behaviors, advocate for further mental health funding, as well as refer students struggling to treatment and recovery programs ${ }^{[5]}$. According to Knopf, school counselors need to be mindful that students struggling with untreated mental illnesses are more likely to develop a substance use disorder, as well as students who experience chronic stress or who have endured traumatic experiences. Many students who have a mental illness or who are struggling with extenuating stressful circumstances are more likely to engage in substance usage ${ }^{[5]}$. Routine screenings, brief interventions, and referral to treatment is recommended for students who are engaging in at risk behaviors, as brief counseling has been shown to reduce drug misuse amongst adolescents ${ }^{[5]}$. The implementation of school-based programs in conjunction with health care support is imminent in order to reduce drug misuse amongst teenagers.

Although drug usage is a complex issue that is impacted by one's desire, peers, family history, or genetics, there are preventative measures that school counselors can take in order to help students combat substance abuse. Fostering open communication and promoting the importance of parental support is vital when working to mitigate drug usage amongst students ${ }^{[5]}$. Moreover, one of the most impactful ways for school counselors to help reduce drug usage amongst students is by creating a comprehensive, community based, and school supported prevention $\operatorname{program}^{[6]}$. Comprehensive programs address three main stakeholders including the user, the affected, and the non-user and have curricula to raise awareness for those involved. There are specific entities that need to be integrated into comprehensive counseling programs in order for them to be successful in helping students to mitigate their drug usage.

\section{Comprehensive Counseling Programs}

There are several components that are necessary to include in order for counselors to develop comprehensive counseling programs within their schools. Each component will be addressed in further detail below.

Educate the Educators: First and foremost, counselors need to educate the educators (teachers, administrators, parents, nurses, students) about the dangers and long term consequences of drug usage. Stakeholders need to be aware of common knowledge, signs and symptoms, as well as the ways in which drug usage negatively impacts students academically and personally. Stakeholders also need to be aware of resources available to help students who are struggling with or knows someone struggling with substance abuse and refer them to Al-Anon, Alateen or another support group.

Review Policies and Procedures: The second component addressed when developing a comprehensive counseling program is ensuring that all policies are reviewed and updated to ensure that they reflect the school's ideals and philosophy. Research has shown that when chemical dependency is viewed as a disease, this allows for the focus to be reframed into a positive way to help students rather than to isolate or punish them in a punitive manner ${ }^{[6]}$. It is advantageous for policies to emphasize the importance of making healthy choices and decisions in the future. Students who have the ability to make more constructive choices experience more freedom, independence, and autonomy, which further enhances academic performance since they focus on building upon their strengths and pursuing their passions.

Create a Healthy School Climate: Another component that needs to be incorporated into building a school counseling comprehensive program is for counselors to help create a maintain a healthy school climate. Students need to feel accepted, safe, included, challenged, and supported. Through creating a positive strengths based environment, students are able to excel both academically, socially, and feel more comfortable approaching an educator if they are struggling with an issue ${ }^{[6]}$. One of the most important components to student success is the alliance he or she shares with the counselor, as they are the liaison between the school, family, and community and the student's greatest advocate. Schools also need to emphasize the importance of consistency in regards to remaining drug free both at home and school and reinforce the negative impact that drug usage has on people personally and professionally. Schools that develop healthy and stimulating climates that engage students socially and academically, have students and faculty that are more respectful, caring, supportive, cohesive, and trustworthy. It is imperative for school counselors to facilitate discussion about drug usage in an open and honest manner, as this educates students, enables them to make more constructive decisions, encourages them to engage in higher order critical thinking, allows students to feel more comfortable disclosing personal information regarding drug usage, 
as well as promotes the importance of having a drug free school with successful and healthy constituents.

Engage Community in Drug Abuse Prevention: Another tactic that school counselors can use in order to help students reduce drug usage is to engage the community about drug abuse prevention. Through education and outreach counselors can help mitigate drug usage in their schools ${ }^{[6]}$. School counselors also need to be encouraged to collaborate with law enforcement in order to decrease the supply and of drugs within the community. This is especially important regarding Heroin due to its availability and affordability. Additionally, parental involvement is vital in the reduction of drug usage. Parents need to know where their children are and their expectations about not engaging in drug use. Counselors can conduct workshops for parents on the consequences of drug usage and motivate them to monitor and be mindful of their children's academic performance, actions, changing behaviors, and symptoms; as these can all be indicative of substance usage.

Support Groups: Support groups in the school setting are vital so that students feel that they can share their thoughts, fears, perceptions in an open, safe, and supportive environment that is inclusive. Support groups are extremely beneficial as they provide students with support and normalize what is taking place in their lives. Being around other students who engage in drug usage or who have friends or family members who utilize substances, helps students to feel understood and prevents them from feeling ostracized, which can lead to further drug usage. Counselors need to offer help to students who are seeking assistance, support, mentorship and guidance. Without having support groups in the school setting or being referred to outside support groups, student likelihood of abstinence greatly decreases ${ }^{[6]}$. Students may use drugs themselves or have friends or family members who use drugs and they are in dire need of having a safe place to talk about their concerns, otherwise they may struggle with feelings of helplessness, guilt, shame, powerlessness, and fear. Support groups also provide students with the opportunity to learn and practice refusal skills, which are necessary to master in order to prevent drug usage.

Promote Student Awareness: Counselors can also promote student awareness about the importance of abstaining from drug use by conducting large group presentations, having anti-drug use campaigns, showing clips or films addressing the dangers of drug usage, or hold assemblies on the dangers of drug usage; particularly Heroin due to its debilitating and highly addictive nature. Counselors can teach students about the disease model and chemical dependency, as well as mentor and support those who are trying to maintain sobriety. Further, counselors can also provide students and families the names and contact information of outside counseling agencies, support groups, or rehabilitation center if their drug usage is concerning and they desire to become sober.

Develop Athletic Peer Leader Programs: Athletes in the school setting have leadership positions and they act as role models for other students to emulate. Therefore, counselors can also educate athletes about the dangers of drug usage, discuss the ways in which drugs will impede upon their judgment, and how drug usage can negatively impact their performance on and off of the field ${ }^{[6]}$. Training athletes to become peer leaders who denounce drug usage is beneficial as these students can use their platform to spread the message that drug usage is harmful, impedes upon one's abilities, achievement of goals, and dreams, which will hopefully help to reduce substance usage amongst fellow peers.

School Counseling Best Practices: According to SAMH$\mathrm{SA}(2004)$ only $8.1 \%$ of teenagers who needed drug treatment received treatment in a facility due to lack of resources allocated for drug usage, small numbers of intervention models, and limited access to rehabilitation services. Due to the limited amount of community services offered, brief school based interventions and programs facilitated by school counselors have gained popularity ${ }^{[7]}$. There are several key elements that need to be incorporated into effective school based interventions for drug abusing adolescent students. First, the effectiveness of interventions are largely impacted by timing, duration, frequency, and intensity of exposure to the intervention ${ }^{[7]}$. Effectiveness of interventions is enhanced before the onset of significant substance abuse issues. Secondly, programs need to be delivered with fidelity; counseling delivery needs to be standardized and counselors need to be monitored. Third, the school needs to recognize the extent of the problem; specifically Heroin usage, and all stakeholders must be proactive in creating a positive and drug free school climate. Lastly, the counseling program needs to take into account other influences in students' lives such as their neighborhood, family, and peers as those entities have a direct impact on student choices.

Brief Interventions: Brief interventions are used frequently in schools; especially when counseling students struggling with substance abuse issues. Brief interventions have the highest effect size amongst all treatments for abuse and dependence ${ }^{[7]}$. Brief interventions are client centered and tailored to meet the needs and goals of students. Also, they are engaging and require student participation making it a collaborative learning process. Brief interventions integrate motivational enhancement strategies that encourage students to change destructive behaviors. Brief interventions are typically brief in nature lasting from two to four one hour sessions and incorporate Motivational Interviewing, which raises student awareness, offers options for change, as well as holds the student accountable for making positive changes ${ }^{[7]}$. Motivational Interviewing helps students to recognize their struggles and to set goals for change and mandates counselors to express empathy (listen rather than talk/accept student) avoid argumentation (avoid confrontation and encourage student to make positive changes), roll with resistance (directing student towards making positive changes), develop discrepancies (promote student awareness of consequences of continue substance use) and support self-efficacy (support hope and encourage student to reach goals $)^{[7]}$. Brief Interventions have shown to mitigate drug usage amongst adolescents (Knopf, 2016). Additionally, according to Winters et al., ${ }^{[7]}$, brief interventions are effective to use with adolescents in that they help to reframe students' mindset that heavy drug usage is normative for themselves and their peers and helps them to recognize the dangers of drug usage. Additionally, brief interventions are non-confrontational which is also important when working with adolescents so that they do not become defensive and shut down. Further, Brief Interventions are focused on client change and are proactive and action oriented, which helps the student to be en- 
gaged in the counseling process and encourages them to focus on their present and future goal setting rather than on the past $\mathrm{t}^{[7]}$.

Social Resistance Skills Training: Social resistance training is designed with the goal of making adolescents more cognizant about the social influences that support substance use, as well as teaching them skills for resisting peer and media influences ${ }^{[8]}$. Resistance training programs teach students to avoid or cope with social situations that may involve substances. Students are taught how to effectively address peer pressure by knowing what to say (using refusal messages) and ways to deliver their refusal messages in the most powerful ways possible.

Normative Education: Normative education approaches include content and activities to rectify inaccurate perceptions regarding the prevalence of substance usage ${ }^{[8]}$. Many teenagers overestimate the usage of drugs; particularly Heroin, which can normalize substance abusive behaviors. School counselors need to educate students about the factual rates of substance usage, which will in turn help to change perceptions about the social acceptability of drug usage. Counselors can research and present data from national surveys addressing the prevalence in order to further validate the facts.

Competence Enhancement: Coping enhancement programs emphasize the importance that social learning processes are relevant in the development of drug usage in teenagers. These programs address that teenagers with poor coping skills and social skills are more likely to use drugs. Competence enhancement programs teach students life skills including general problem solving and decision-making skills, general cognitive skills for resisting interpersonal or media influences, skills for increasing self-control or self-esteem, adaptive coping strategies for relieving stress and anxiety through using coping skills and relaxation techniques, as well as teaching students social and assertiveness building skills. The purpose of Competence Enhancement programs is to teach students life skills that they can utilize inside and outside of the classroom, as well as to provide them with the strength and ability to remain drug free and deal with challenging situations in a calm and practical manner ${ }^{[8]}$.

Life Skills Training Program: The Life Skills Training Program (LST) influences the social and psychological factors that impact substance usage. The program is an evidence based program that has been shown to have positive outcomes on helping students to reframe normative beliefs about substance usage and improve substance refusal skills. It can be used with elementary, middle, and high school aged student. Program content integrates cognitive behavioral techniques including instruction, demonstration, feedback, social reinforcement, as well as behavioral homework assignments. The program is comprised of three major components that identify critical domains that promote substance usage. One of the components includes teaching students about drug resistances skills that allow students to recognize and challenge misconceptions about substance usage, as well as teaches students how to overcome peer pressure ${ }^{[9]}$. The second component includes teaching students personal self-management skills to help them enhance their self-image, set goals and keep track of their personal progress, identify decisions, analyze problem situations, and be mindful of outcomes of decisions made ${ }^{[8]}$. The third component enables students to build their social skills in order to assist them in overcoming feelings of shyness, how to communicate effectively, enhance their assertiveness skills, as well as teach them how to make refusal statements.

Project towards No Drug Abuse: Project Towards No Drug Abuse (TND) is a high school program that is designed to help students at-risk to resist substance usage ${ }^{[8]}$. TND is composed of twelve 40 to 50 minute sessions that incorporate motivational activities, social skills training, and decision making components. The program is delivered through group discussions, games, role plays, videos, and worksheets. TND addresses the reduction of alcohol usage, tobacco, and other illicit substances. The program teaches students to be mindful of motivational factors including attitudes, beliefs, and expectations regarding substance usage, social, self-control, coping skills, decision making skills, and teaches students how to make positive decisions that lead to health behaviors ${ }^{[8]}$. The program encapsulates the belief that students will not use substances if they are aware of misconceptions that lead to drug use, have adequate coping skills, are mindful of long term consequences, are knowledgeable about cessation strategies for quitting drug use, and possess strong decision making skills ${ }^{[8]}$.

Brief Strategic Family Therapy: Brief Strategic Family Therapy (BSFT) is an evidence based family-based intervention that focuses on decreasing individual and family risk factors by improving and strengthening family relationships ${ }^{[8]}$. Many times adolescents who are struggling with drug usage will not seek treatment until family members become aware of the severity of the problem ${ }^{[5]}$. BSFT has shown to elicit positive outcomes in regards to enhancing family engagement, increasing and demonstrating support, while also potentially decreasing substance usage amongst family members. BSFT is most effective to utilize with students who engage in delinquent behaviors, as well as those using or associating with peers who use substances. The program is also helpful for families who experience discord, behavioral difficulties or disengagement due to substance usage. Counselors are trained to develop a strong therapeutic alliance with the family, to encourage the family to identify strengths, supportive relationships, identify problematic relationships, as well as to implement change strategies that help family members to change the meaning of their interactions, shift boundaries, enhance conflict resolution skills, and provide parental coaching ${ }^{[8]}$.

\section{Implications for the School Counseling Field}

Due to the fact that Heroin use amongst adolescents has heightened significantly over the past decade, there is a danger for adolescents resulting in psychological, social, educational, and legal consequences ${ }^{[9]}$. Adolescent drug abuse is a complicated issue that incorporates the family, relationships, school, peers, and the community at large. School personnel, specifically school counselors must be mindful of warning signs such as inconsistent academic performance, truancy, and moodiness, so that early intervention and prevention is possible. School counselors are encouraged to be cognizant of his or her own perceptions about the student's changing behaviors. The counselor can also ask the student an open ended question regarding their self-esteem, current life situations such as having poor family relationships, if there is a family history of substance use, if he or she has been engaging in risky behaviors, poor coping skills, reduced academic performance, disciplinary problems, or mood 
changes.

Many students who are engaging in substance usage may be resistant, and therefore school counselors can provide systemic support, intervention, and consultation in order to help students struggling with substance issues. Consultation is a method of applying counseling services to a student systemically and indirectly in which the counselor serves as a student advocate ${ }^{[10]}$. The most common form of consultation in schools is using a triadic nature where the counselors work with either a teacher or parent about a concern they have about a student. The parent or teacher collaborates with the counselor and then the counselor implements the strategy discussed with the student to help them reduce their drug usage. Students who use Heroin may need several consultees as that addiction necessitates both school and agency rehabilitation. School counselors can also utilize a school based collaborative consultation in which the counselor becomes the coordinating consultant and they provide and coordinate information and strategies that best meet the student's needs ${ }^{[9]}$.

School counselors are trained in consultation and work to support all students. School counselors have a specific responsibility to create and support a drug free school. In regards to addressing Heroin usage amongst students in schools, a systems theory must be used and counselors need to look at the interpersonal dysfunctionality that may exist within the student's family dynamics. School counselors are aware that in order for positive changes to occur within the student's life, changes within their system need to be made. Many issues that students face are due to family function or dysfunction. Thus, systemic interventions or family meditations are necessary when students are abusing Heroin. When working with students using Heroin, counselors need to work with the family, school, and outside mental health agencies to ensure their well-being and recovery process

Moreover, school counselors must consult with the family, as family involvement is vital when students are struggling with Heroin use. Counselors can act as liaisons, offer referral services, and support the student and their family. It is important for counselors to approach family members in a non-confrontational manner so they do not feel threatened or blamed ${ }^{[9]}$. School counselors also need to consult with other school personnel and share information with them concerning the student. School counselors can hold educational trainings for other stakeholders addressing the consultation process about trends in adolescent Heroin use, the warning signs, and services offered for students and their families. School counselors need to collaborate with teachers and stakeholders and form a partnership in order to support students and their families.

Additionally, school counselors are encouraged to consult with community agencies because school counselors are not trained or licensed to provide substance counseling for their students. The most appropriate services that school counselors can offer students using Heroin, is to act as a consultant, liaison, and to connect the student and his or her family to community agencies that provide adequate services ${ }^{[9]}$. Counselors can provide students and their families to Narcotics Anonymous, rehabilitation centers, as well as provide them with crisis hotline intervention numbers if there is an emergency being experienced. American School Counseling Association (ASCA) mandates that $80 \%$ of school counselors spend their time directly interacting with students, personnel, and their families including conducting con- sultation, classroom workshops, individual and group counseling, family education, referrals, and mediation for students who are struggling with Heroin abuse ${ }^{[9]}$.

\section{Conclusion}

Heroin usage amongst adolescents has become an epidemic over the past ten years and is increasing rapidly. School counselors are in the unique position to support and advocate for students at risk for abusing drugs by intervening and providing preventative services including consultation with stakeholders and family members, mediation, workshops, and individual or group counseling for students in need. This paper addresses the instrumental role that school counselors play in regards to identifying students who are struggling, providing school based interventions, and providing them with necessary referrals if the student needs outside counseling or rehabilitation. Although research has been conducted regarding the role that school counselors play in helping students to reduce their drug usage, there needs to be more research carried out in order to determine the most efficacious modalities to use in the school setting, as well as to identify the techniques within those modalities that elicit the most positive outcomes for students abusing Heroin. Further, more research needs to be done to determine other ways in which school counselors can provide consultation for students and their family members. It would be advantageous to have more courses offered in school counseling Master's programs in consultation, so that all school counselors are aware of the consultation process, the components it entails, and its impact on mitigating Heroin usage amongst students and family members.

Despite the long-term consequences that adolescent students who use Heroin may face, school counselors have the ability to intercede early on in order to prevent further Heroin usage amongst students. School counselors can help students identify underlying reasons for using substances, help raise awareness about the dangers of Heroin usage, motivate students to enhance their coping skills, self-worth, assertiveness, self-efficacy, refusal skills, as well as to encourage students to build upon their strengths, so that Heroin use does not overpower or overshadow their academic, personal/social, or vocational hopes, goals, abilities, and dreams.

Author Biography: Allison C. Paolini, Ph.D., NCC is an Assistant Professor of Counselor Education at Kean University in the Nathan Weiss Graduate College. Dr. Paolini has presented at numerous national and state conferences addressing a variety of prevalent issues within the counseling field. Dr. Paolini has previously worked as a School Counselor. Her areas of research interest include the use of accountability measures and their impact on student academic success, as well as closing the achievement gap, evidence-based practices school counselors can utilize to enhance academic achievement and emotional wellness of all students, proactive strategies to combat bullying, counseling interventions to decrease student violence, and substance usage and its impact on student academic performance and well-being. 


\section{References}

1. National Institute on Drug Abuse. (2014) Drug Facts: Treatment Statistics.

2. King, K. M., Meehan, B., Trim, R., et al. Substance use and academic outcomes: Synthesizing findings and future directions. (2006) National Institutes of Health 101(12): 1688-1689.

3. Palamar, J., Shearston, J., Dawson, E. J., et al. Nonmedical opioid use and heroin use in a nationally representative sample of high school seniors. (2016) Drug and Alcohol Dependence 158: 132138 .

4. Cerda, M., Santaella, J., Marshall, B. D., et al. Prescription opioid use in childhood and early adolescence predicts transitions to heroin use in young adulthood: A national study. (2015) J Pediatr 167(3): 605-612.

5. Knopf, A. Report: To reduce teen substance use, create resilience, and treat mental illness. (2016) The Brown University Child and Adolescent Behavior Letter 3-5.

6. Farrell, T. (2007) Drug prevention in the $21^{\text {st }}$ century.

7. Winters, K. C., Leitten, W., Wagner, E., et al. (2007) Use of brief interventions for drug abusing teenagers within a middle school and high school setting. J Sch Health 77(4): 196-206.

8. Griffin, K., Botvin, G. Evidence based interventions for preventing substance use disorders in adolescents. (2010) Child Adolesc Psychiatr Clin N Am 19: 505-526.

9. Lambie, G. W., Davis, K. M. Adolescent heroin abuse: Implications for the consulting professional school counselor. (2007) Journal of Professional Counselling: Practice, Theory, \& Research 35(1): 1-17.

10. Alexandria, V.A. The ASCA national model: A framework for school

counselling programs. (2003) American School Counselor Association.

Ommega Online Publishers

Journal Title: Journal of Addiction and Dependence(JAD)

Journal Short Name: J Addict Depend 